\title{
Overview of leaching remediation of heavy metal contamination in soil
}

\author{
Cui Shuang ${ }^{1, *}$, Han Qing ${ }^{2}$, Zhang Tianyi ${ }^{1}$ \\ ${ }^{1}$ College of Environmental and Chemical Engineering, Shenyang Ligong University, Shenyang, Liaoning, 110159, China \\ ${ }^{2}$ School of Materials \& Metallurgy, Northeastern University, Shenyang, Liaoning, 110819, China
}

\begin{abstract}
The remediation methods of heavy metal contaminated soil can be divided into bioremediation, physical remediation and chemical remediation. Chemical remediation mainly includes soil leaching and chemical curing. There are two kinds of soil leaching remediation methods: in situ soil leaching remediation and ectopic leaching remediation. The eluent of heavy metals in soil includes inorganic eluent, chelating agent, surfactant and so on. Soil leaching can be applied to the remediation of contaminated soil alone or combined with other remediation methods.
\end{abstract}

\section{Introduction}

Natural heavy metals in the soil, generally will not cause harm to the environment. However, due to human activities, such as coal burning, electroplating, mining, chemical industry, waste incineration and other industries discharge three wastes, pesticides, fertilizers and pollution in farmland promote the biogeochemical cycle of heavy metals, so that the release of heavy metals is increasing, and most of them enter the soil. Heavy metals accumulated in soil not only harm soil ecosystem, but also pollute surface water and groundwater through runoff and leaching, pollute hydrological environment, and even endanger human health through direct contact and entry into food chain.

The method of soil elution and remediation refers to the process of elution and cleaning of pollutants in soil by injecting leaching agents, such as water or aqueous solution containing washing aids, acid or alkali solution, chelating agent or surfactant into contaminated soil or sediment. After treatment, the collected waste liquid is discharged, and the leached soil can continue to be used safely [1]. Evans [2] summarizes the mechanism of soil metal retention: one is adsorption on the surface of soil components in the form of ions, the other is the precipitation of metal compounds. The mechanism of soil elution is to generate soluble heavy metal ions or metal complexes by reversing these reaction [3], and then these pollutants rush out of the soil with the leaching agent.

\section{Soil leaching remediation techniques}

In recent years, with the acceleration of urbanization and the transformation of many heavy industrial cities in China, many industrial sites have been idle. Due to the long-term extensive development model of polluting enterprises, there are often a large number of toxic and harmful substances in these polluted soils, which seriously affect the ecological environment and the safety of human settlements. Among them, the problem of soil pollution caused by heavy metal pollutants such as lead, mercury, cadmium, chromium, nickel and similar arsenic is particularly prominent. There are two kinds of soil leaching remediation methods: in situ soil leaching remediation and ectopic leaching remediation.

\subsection{In situ soil leaching remediation techniques}

In situ soil leaching remediation technology refers to the construction of remediation equipment in situ in contaminated areas, through the application of eluent from the ground to the soil, the eluent permeates into the soil, and then interacts with the pollutants in the soil. In this process, through desorption, dissolution or complexation, the pollutants are removed from the soil by the eluent and bound by the eluent, and finally the transferable compounds are formed. Eluent can be collected by extraction wells for reasonable storage and treatment. The treated eluent can be reused in contaminated soil remediation [4]. The main defect of this kind of repair technology is that it can not control the specific flow direction of the leaching liquid, and the leaching liquid is easy to flow into the unclear area. When using this technology, the hydrological data of the local area should be understood in detail in advance [5].

\subsection{Ectopic soil leaching remediation techniques}

Ectopic soil leaching remediation technology refers to excavating the contaminated soil, removing large impurities, then cleaning and removing pollutants with cleaning liquid, then recycling the leaching solution

\footnotetext{
* Corresponding author: ccshuang@163.com
} 
containing pollutants after treatment, and finally backfilling the treated soil [4]. Ectopic elution repair technology usually needs to use external force to improve the removal effect. The commonly used external force is stirring, but the efficiency of stirring is on the low side. In recent years, ultrasonic elution is often used, which is a high efficiency and low energy consumption [6]. Ectopic soil cleaning is one of the commonly used techniques in remediation of contaminated soil. The equipment of this method is transferable, can be built and modified anytime and anywhere, and has high remediation efficiency and great application value [7].

\section{Classification of eluent for soil leaching remediation}

Eluent of heavy metals in soil includes inorganic eluent, chelating agent, surfactant and so on.

\subsection{Inorganic leaching agents}

Water, acid, alkali, salt and other inorganic solutions are commonly used inorganic eluents. They are mainly used to wash heavy metals in contaminated soil. The mechanism of action is acid hydrolysis, complexation or ion exchange, destroy the soil surface functional groups, then form complexes with heavy metals, cause heavy metals to be released [8]. Compared with other leaching agents, inorganic leaching agent has the characteristics of fast action, low cost and good removal effect. Common inorganic eluent including $\mathrm{HCl}, \mathrm{HNO}_{3}, \mathrm{H}_{2} \mathrm{SO}_{4}$, $\mathrm{H}_{3} \mathrm{PO}_{4}, \mathrm{NaOH}, \mathrm{CaCl}_{2}, \mathrm{FeCl}_{3}$, etc. According to Liu Lei et al [9], the optimum elution effect can be achieved by 2 mol L ${ }^{-1} \mathrm{HCl}$ under the condition that the soil-liquid ratio is $1: 3$ and the elution time is $1 \mathrm{~h}$ for 2 times, Cd removal rates up to $95.52 \%$, and can effectively remove various forms of heavy metals in soil.

\subsection{Chelating agents}

Chelating agents can be widely used as eluent because of their strong metal activation ability. The commonly used chelating agents are synthetic chelating agents and natural chelating agents. The mechanism of chelating agent is divided into two processes: analytical and complexation. Firstly, the heavy metal ions adsorbed on the surface of soil components are analyzed, and then the strong chelation is used to form a strong complex with the heavy metal ions, so the heavy metal ions in the soil can be separated [8].

\subsubsection{Synthetic chelating agents}

The common artificial chelating agents include: ethylenediamine tetraacetic acid (EDTA), ethylenediamine disuccinate (EDDS), aminotriacetic acid (NTA), diethyltriamine pentanoic acid (DTPA), etc. (Fig.1). Synthetic chelating agents are very effective soil eluent, can form stable complexes with heavy metals in a wide range of $\mathrm{pH}$, which not only insolubling heavy metal compounds, but also desorbing heavy metals adsorbed by soil.<smiles>O=C(O)CN(CCN(CC(=O)O)CC(=O)O)CC(=O)O</smiles>

EDTA structure<smiles>O=C(O)CC(NCCNC(CC(=O)O)C(=O)O)C(=O)O</smiles>

EDDS structure<smiles>O=C([O-])CN(CC(=O)O)CC(=O)O</smiles>

NTA structure<smiles>O=C(O)CN(CCN(CC(=O)O)CC(=O)O)CCN(CC(=O)O)CC(=O)O</smiles>

DTPA structure

Fig.1 The structure of common synthetic chelating agent

According to Zhou et al [10], $0.05 \mathrm{~mol} / \mathrm{L}$ EDTA solution eluting for 18 hours at a $\mathrm{pH}$ value of 7 , the removal rate of heavy metals from contaminated soil was the best. However, artificial chelators have their limitations, including poor biodegradability, high price, high cost, prone to secondary pollution of soil and groundwater [11]. Besides, there are still technical problems in the subsequent recovery of heavy metals, resulting in limitations in actual repair.

EDTA (ethylenediamine tetraacetic acid), EGTA (ethylene glycol diethylenediamine tetraacetic acid), HEDTA (hydroxyethylenediamine triacetic acid), DTPA (diethylenediamine pentaacetic acid) are widely used as chelating agents in soil remediation experiments, and many studies have demonstrated that EGTA has strong 
activation ability and good selectivity for heavy metals. However, as the research progresses, it is found that EDTA is toxic to plants and microorganisms, and these chelating agents are biodegradable slowly or not easily degraded, and activated heavy metal chelates percolate deep into the soil, leading to secondary pollution. Aiming at the above problems, people began to advocate the use of biodegradable chelating agents to gradually replace refractory chelating agents, such as low molecular weight organic acids, EDDS (ethylenediamine succinate) and so on. low molecular organic acids are easy to degrade, but their chelating ability is much weaker than EGTA and so on. EDDS can be produced by microorganisms, the toxicity is low, it is easy to degrade, and the degradation products are harmless, but its chelating effect on heavy metals is still weaker than EGTA and so on.

The mechanism of chelating agent strengthening phytoremediation is in soil and plant. The process of soil action refers to the chelating agent promoting the desorption and release of heavy metals from soil particles into soil solution, increasing the probability of plant absorbing heavy metals. Plant action includes enhancing plant tolerance to heavy metals and promoting heavy metal transport to plant surface. The effect of chelation induction depends not only on plant species, heavy metal types, but also on the physical and chemical properties of soil and the use of chelating agents.

The chelating agents used in remediation of heavy metal contaminated soil are ethylenediamine tetraacetic acid (EDTA), ethylene glycol bistetraacetic acid (EGTA), $\mathrm{N}$-hydroxyethylenediamine triacetic acid (HEDTA) and other, but the biodegradability of these chelating agents is poor, which can easily cause heavy metal leaching and may cause secondary pollution of surface water and groundwater. Therefore, the research and development of biodegradable chelating agents is a hot in this field. Biodegradable chelators for enhanced phytoremediation mainly include amino carboxylic acid chelators, organic phosphonic acid chelators and so on.

\subsubsection{Natural chelating agents}

Typical natural chelating agents include citric acid, malic acid, malonic acid, oxalic acid and other types of natural organic substances (Fig.2).

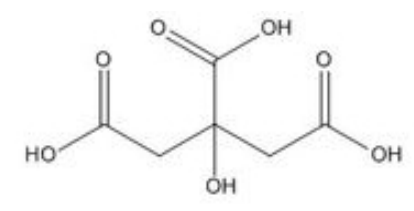

citric acid structure<smiles>O=C(O)CC(O)C(=O)O</smiles>

malic acid structure<smiles>O=C(O)CC(=O)O</smiles>

malonic acid structure<smiles>O=C(O)C(=O)O</smiles>

oxalic acid structure

Fig.2 The structure of typical natural organic acid

$\mathrm{Hu}$ et al. used citric acid, tartaric acid, oxalic acid solution in the tested soil for elution experiment [12]. The results showed that they all had desorption effect on the $\mathrm{Cd}$. In the elution of $\mathrm{Cd}$, under the same low molecular organic acid concentration elution conditions, the removal capacity of each low molecular organic acid was in the order of citric acid $>$ tartaric acid $>$ oxalic acid.

Compared with the synthetic chelating agent, the molecular weight of natural organic acids is small, and the migration and activity of heavy metals can be improved by forming soluble chelates with heavy metals. Because of their excellent characteristics, degrade quickly, low price, and no secondary pollution to the environment, natural organic acids can effectively repair the soil contaminated by heavy metals. They are environmentally friendly chemical eluents [13].

\subsection{Surfactors}

The molecular structure of surfactant has amphiphilicity: one end is hydrophilic group and the other end is hydrophobic (hydrophobic) group, which makes the surfactant can dissolve in water and gather at the phase interface [14]. They mainly include chemical surfactants and biological surfactants, which can significantly reduce the surface tension of the system. When exceeding the critical micelle concentration, they form micelles inside the solution and then produce functional such as solubilization, emulsification, wetting, dispersion and washing [15].

\subsubsection{Chemical surfactants}

Chemical surfactant refers to one end of hydrophilic group, one end of the long chain organic matter, such as fatty acid sodium, fatty alcohol sodium sulfate, fatty alcohol polyoxyethylene ether. The chemically synthesized surfactants can effectively reduce the adsorption of heavy metal $\mathrm{Cd}$ in clay. The chemical surfactants have good solubilization effect and short period, but they are not easy to decompose and can not be biodegradable. It is easy to remain in the process of elution and repair, which will cause harm to the environment [16], also cause anaerobic odor in water. 


\subsubsection{Biosurfactants}

Biosurfactants are surface active compounds produced by microbial metabolism such as bacteria, fungi and yeast, which are generally polycyclic organic compounds containing phenolic hydroxyl groups. Most of the biosurfactants produced by microbial metabolism are anionic or nonionic. Biosurfactants such as saponin, are active components of saponin, natural glucoside compounds and natural nonionic surfactants, which are the main representative of biological surfactants produced by plants [17]. Biosurfactants have the characteristics of non-toxic or low toxicity, easy selfdegradation and small environmental pollution, and have a broad application prospect in remediation of heavy metal contaminated soils [18].

\section{Conclusions and prospects}

At present, the application of soil leaching method in remediation of heavy metal contaminated soil has made some achievements, but there are still some shortcomings and limitations, mainly for the soil with sticky texture and poor permeability. The better leaching agent can not realize large area soil remediation because of its high price, the residual leaching agent is easy to cause secondary pollution in soil, and the reasonable treatment of leaching waste liquid containing heavy metals is also a difficult problem.

The key of soil elution remediation is the selection of eluent, which can not only extract heavy metals from various forms, but also do not destroy the structure of soil. Therefore, in the future, the focus of leaching remediation of heavy metal contaminated soil will be on the improvement of the original eluent and the development of new eluent.

\section{Acknowledgements}

This work was financially supported by National Natural Science Foundation of China (41773093).

\section{References}

1. Y.M. Luo, Chem. Prog., 21, 2 (2009)

2. L.J. Evans, Environ. Sci. Technol., 23, 9 (1989)

3. X.X. Long, X.E. Yang, W.Z. Ni, J. Appl. Ecol., 13, 6 (2002)

4. D. He, T. Zhou, S.B. Yuan, et al. Sichuan Environ., 29, 5 (2010)

5. Q. Zhao, Northwest University of Agriculture and Forestry Science and Technology, (2011)

6. G.D. Ji, G.H. Zhou, J. Beijing Univ., 43, 6, (2007)

7. Y.F. Jin, L.J. Zhou, Environ. Sci. Technol., 25, 5, (2011)

8. X. Ke, P.J. Li, Z.Q. Gong, et al. J. Ecol., 23, 5, (2004)

9. L. Liu, S.P. Hu, Y.X. Chen, et al. J. Appl. Ecol., 6, (2010)
10. J.G. Zhou, X.D. Cai, Y.Q. Wang, et al. Guangzhou Environ. Sci., 24, 2, (2009)

11. Y.J. Sun, J. Song, Y.H. He, J. Qingdao Univ.Tech., 30, 5, (2009)

12. H. Hu, J. Pan, Q.R. Zeng, et al. J. Agr. Environ. Sci., 27, 4, (2008)

13. G.L. Gao, W. Zhang, L.B. Zhou, et al. Non-Ferr. Met. Eng., 1, (2013)

14. Z.W. Zhang, Shandong Agr. Univ., (2009)

15. S.R. Wang, X.G. Li, D.Z. Liu, Surfactant Chemistry [M]. Chemical Industry Press (2005)

16. X. Liu, Northwest University of Agriculture and Forestry Science and Technology, (2012)

17. Y.T. Meng, X.Z. Yuan, G.M. Zeng, et al. J. Ecol., 24, 6, (2005)

18. Hao C.L., Agri. Bull. Anhui, 16, 9, (2010) 